\title{
Reflections On the Use of Complexity- Appropriate Computational Modeling for Public Policy Evaluation in the UK
}

\author{
Dr. Pete Barbrook-Johnson \\ Department of Sociology, University of Surrey, UK \\ p.barbrook-johnson@surrey.ac.uk \\ Dr. Corey Schimpf \\ The Concord Consortium, USA \\ cschimpf@concord.org \\ Prof. Brian Castellani \\ Department of Sociology, Durham University, UK \\ brian.c.castellani@durham.ac.uk
}

\section{Acknowledgments}

We would like to thank everyone who worked with us on COMPLEX-IT and in CECAN for their intellectual support and for helping to inform the wider research program which allowed us to conduct this work. This work was supported by the Economic and Social Research Council [grant numbers ES/N012550/1 and ES/ S000402/1].

\begin{abstract}
In the UK, calls for the application of insights from the study of complex adaptive systems to public policy evaluation are beginning to be taken seriously in government. Policymakers and analysts are accepting the fallibility of overly simplistic, definitive, or linear analysis, or are finding traditional forms of analysis and evidence less appropriate or feasible. Through our work in CECAN (the Centre for the Evaluation of Complexity Across the Nexus), we reflect on our experiences and the practical challenges of using complexity-appropriate computational modeling with policy ana-
\end{abstract}


lysts and evaluators in UK central government. As an example, we discuss our work with the COMPLEX-IT toolkit, which uses a selection of case-based computational modeling approaches. We end by suggesting ways forward for applied complexity scientists, and policy evaluators and analysts to make more effective use of these methods.

Keywords: complexity; policy; evaluation; social complexity; research impact

\title{
Reflexiones Sobre el Uso de Modelos Computacionales Adecuados a la Complejidad Para la Evaluación de Políticas públicas en el Reino Unido
}

\begin{abstract}
RESUMEN
En el Reino Unido, los pedidos para la aplicación de conocimientos del estudio de sistemas adaptativos complejos a la evaluación de políticas públicas están comenzando a tomarse en serio en el gobierno. Los formuladores de políticas y los analistas están aceptando la falibilidad de un análisis demasiado simplista, definitivo o lineal, o están encontrando formas tradicionales de análisis y evidencia menos apropiadas o factibles. A través de nuestro trabajo en CECAN (el Centro para la Evaluación de la Complejidad A Través del Nexo), reflexionamos sobre nuestras experiencias y los desafíos prácticos del uso de modelos computacionales con analistas de políticas y evaluadores en el gobierno central del Reino Unido. Como ejemplo, analizamos nuestro trabajo con el kit de herramientas COMPLEX-IT, que utiliza una selección de enfoques de modelado computacional basados en casos. Terminamos sugiriendo formas de avanzar para que los científicos de complejidad aplicada y los evaluadores y analistas de políticas hagan un uso más efectivo de estos métodos.
\end{abstract}

Palabras Clave: complejidad, política, evaluación, complejidad social, impacto de la investigación 


\section{对运用适度复杂的计算建模评 估英国公共政策的反思}

摘要

对于从研究复杂适应系统到评估公共政策应用洞察力的呼声 开始受到英国政府的关注。决策制定者和分析人员逐渐认可 过于简单和决断的直线性分析不太可靠, 抑或发现传统形式 的分析和证据难以实现或不太合理。笔者通过在CECAN (Nexus 复杂性评估中心) 的研究工作向来自英国中央政府的策略 分析人员和评估人员总结了运用计算建模时所面临的实际挑 战和经验教训。举例来说, 笔者通过运用一系列基于案例的 计算建模方法讨论了 COMPLEX-IT 项目工具箱的研究工作。 最后, 笔者关于应用复杂性科学家、政策评估人员和分析人 员如何更为有效地利用这些方法提供了建议。

关键词：复杂性, 政策, 评价, 社会复杂性, 研究影响

\section{Introduction}

The growing interest in the application of insights and methodological approaches from the study of complex adaptive systems (from now on referred to simply as "complexity") in public policy in the UK is well documented (see, for example, Byrne \& Callaghan, 2014; Byrne \& Uprichard, 2012; Anzola, Barbrook-Johnson, \& Cano, 2017). In ex-post policy evaluation in particular-which is a significant component and focus of public policy analysis in the UK-interest has grown steadily over the last 20 years (Reynolds, Forss, Hummelbrunner, Marra, \& Perrin, 2012; Gates, 2016).
In the evaluation literature (not constrained to UK only), focus has also shifted from early discussions of the theoretical implications of complexity for evaluation (e.g. Sanderson, 2000), to more practical explorations of the contexts in which complexity can be usefully applied (e.g. Barnes, Matka, \& Sullivan, 2003). The fit of complexity with other theoretical, methodological, and empirical traditions has been considered (e.g. Callaghan, 2008; Stame, 2004). In the last few years, as we do here, authors have reflected and reviewed the use of complexity in evaluation, for example, its use directly in evaluation scholarship (Gates, 2016; Mowles, 2014; Walton, 2014), the acceptance and use of complexity in prac- 
tice (Reynolds, Gates, Hummelbrunner, Marra, \& Williams, 2016), and reflections on which parts of the typical evaluation process it can be most useful to (Williams, 2015). The shifting focus of these authors through time reflects the growing use and acceptability of complexity in public policy analysis and evaluation; this shift is representative of the evaluation community in the UK too. This is further evidenced by the recent creation of flagship research centers on evaluation, as in the case of the Centre of Excellence for Development Impact and Learning (CEDIL), and CECAN, which have a strong focus on addressing complexity.

We aim in this paper to continue the development of complexity-appropriate evaluation and further elaborate thinking on one particular strand-the use of complexity-appropriate computational modeling in practice-by sharing our experiences and reflections on its use. We combine our experiences with recent contributions on how to have greater impact from the computational modeling (Gilbert, Ahrweiler, Barbrook-Johnson, Narasimhan, \& Wilkinson, 2018) and policy research (Cairney \& Oliver, 2018) communities.

We use as an example, the casebased computational modeling approaches used in the COMPLEX-IT and SACS toolkits (Castellani, Rajaram, Gunn, \& Griffiths, 2015a; Castellani, Rajaram, Buckwalter, Ball, \& Hafferty, 2015b; Castellani, Barbrook-Johnson, \& Schimpf, 2019), which we have recently used with policy evaluators and practitioners in environmental policy domains in the UK. Importantly, for our purpose here, COMPLEX-IT (which is the companion software for the SACS toolkit, see below) employs specific complexity-appropriate computational modeling approaches including cluster analysis, artificial intelligence and artificial neural nets, data visualization, and case-based microsimulation. Focus on the issues of application of these types of modeling is underdeveloped in the public policy and evaluation literature and deserves further attention (Gilbert et al., 2018). Modeling of these types can be seen as more technically sophisticated and appeal to policy users' excitement around data science and artificial intelligence approaches, but also as expensive, time-consuming, and difficult to understand. We hope to articulate these issues, and others, and plot practical ways forward for applied complexity scientists, and policy analysts and evaluators wanting to use computational modeling.

The rest of this paper is structured as follows. Section 2 introduces COMPLEX-IT, SACS, case-based complexity, and CECAN, and discusses in detail the barriers to the use of computational modeling we encountered. Section 3 introduces contributions from the computational modeling and policy research communities on ways forward, and proposes practical steps for applied complexity scientists. Section 4 summarizes and concludes with a call for more pragmatism, modesty, and co-production. 


\section{CECAN and COMPLEX-IT}

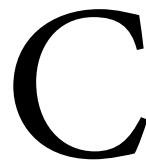

ECAN is a research center hosted by the University of Surrey, in the UK, and made up of partners from nine universities and five policy practitioner and consultancy organizations. It is co-funded by research councils and four government departments or agencies: the Department for Business, Energy and Industrial Strategy (BEIS), the Department for Environment, Food and Rural Affairs (Defra), the Environment Agency (EA), and the Food Standards Agency (FSA). These four departments and agencies give the center its policy focus on food, energy, water, and environment (or "nexus") domains. A nexus approach involves considering the interactions of food, energy, water, and environment domains in a number of ways, see Cairns and Krzywoszynska (2016) for a full discussion.

CECAN's mission is to pioneer, test, and promote innovative evaluation methods and approaches. The work of CECAN is underpinned by complexity and a nexus approach, and the use of co-production and Agile (Senabre Hidalgo, 2018) working methods (CECAN, 2018). As part of its work, CECAN has conducted a range of co-produced case studies with the four departments and agencies and run a fellowship program. One element of this work has involved exploring the application of COMPLEX-IT and casebased methods.

\section{Case-Based Complexity}

Within the world(s) of computational modeling and interdisciplinary mixed-methods, case-based complexity constitutes one of the major methodologies for modeling complex social systems or, more generally, social complexity (Byrne \& Callaghan, 2014; Castellani et al., 2015a). When employed using the techniques of data mining, it is particularly useful for analyzing and modeling policy-based data. To date, there are several different (albeit inter-related) approaches to case-based complexity, such as Ragin's qualitative comparative analysis (QCA) and fuzzy set analysis (Rihoux \& Ragin, 2009 ) and Hayne's Dynamic Pattern Synthesis, which explores the dynamical relationships among cases (Haynes, 2017).

Regardless of the method used, a case-based complexity approach is grounded in four core arguments; which also deeply resonate with the majority of computational methods used in modeling policy data: (i) the case and its trajectory across time and space are the focus of study, not the individual variables or attributes of which it is comprised; (ii) cases and their trajectories are treated as composites (profiles), comprised an interdependent, interconnected sets of variables, factors, or attributes; (iii) the social interactions among cases are also important, as are the hierarchical social contexts in which these relationships take place; and (iv) cases and their relationships and trajectories are the methodological equivalent of complex systems-that is, they are emergent, self-organizing, nonlinear, dynamic, network-like, etc.-and 
therefore should be studied as such.

To this list, our approach to case-based complexity adds three more points which situate case-based complexity even more squarely at the cutting-edge of computational modeling methods: (i) cases and their trajectories are dynamically evolving across time/space; and therefore should be explored to identify their major and minor trends; (ii) in turn, these trends should be explored in the aggregate for key global-temporal patterns; and (iii) the complex set of relationships among cases is best examined using the tools of network science.

\section{COMPLEX-IT and the SACS Toolkit}

Now that we have a basic sense of casebased complexity, we need to quickly review one of its key methodological platforms, the SACS Toolkit (Castellani et al., 2015a), and its companion software, COMPLEX-IT (Castellani et al., 2019), which we have been using with policy evaluators. The utility of the SACS Toolkit (Sociology and Complexity Science toolkit) is that it is a mixed-methods, computationally grounded approach to modeling complex systems, particularly large datasets (Castellani \& Rajaram, 2012; Castellani et al., 2015a; Rajaram \& Castellani, 2015). The purpose of the SACS Toolkit is to provide users with a series of steps and procedures for modeling complex systems in case-based terms; this is supported with full mathematical justification. In line with case-based complexity, the purpose of the SACS Toolkit is to model multiple trajectories (particularly across time/space) in the form of major and minor trends; which it then visually and statistically data mines for both key global-temporal dynamics and unique network-based relationships. The SACS Toolkit also data mines its results to either (a) predict novel cases or trends or (b) simulate different case-based scenarios. For an in-depth overview of the SACS Toolkit, including its mathematical foundation, see http://www.artsciencefactory.com/cases.html.

The software companion to the SACS Toolkit is COMPLEX-IT (http:// www.art-sciencefactory.com/complexit .html). The COMPLEX-IT toolkit is an open-source web-based application in beta development. It was built using the $\mathrm{R}$ shiny framework (see, https:// shiny.rstudio.com/). It uses a tab-driven interface to allow users to easily employ a suite of computational modeling approaches from traditional k-mean cluster analysis to a self-organizing neural network map (SOM), and casebased microsimulation. It is designed to require no prior experience with the techniques so that nonexperts may begin using these methods quickly, and thus whet their appetite to understand the methods more deeply and be encouraged to begin applying them more meaningfully in their analysis. Advanced users can examine, download or modify COMPLEX-IT's algorithms, results, and codebase.

\section{Using COMPLEX-IT with UK Policy Analysts and Evaluators}

Between July 2017 and March 2018, we facilitated a series of workshops with 
policy evaluators and analysts in order to explore the practical challenges faced when using such tools, and to further develop COMPLEX-IT's functionality and usability. Of the various workshops we held, one in particular was relevant here, primarily because it was emblematic of the experiences we had in our other workshops. It is also of interest because the nature of its focus-exploring the application and implementation of a new analysis approach in government, and how complexity-appropriate modeling can help-gave the discussions a high level of practical detail.

The workshop was co-organized with Natural England, and attended by officials from Natural England, Defra, the EA, and the Forestry Commission; these are all public bodies with a range of roles in policy design, implementation, and evaluation, aimed at environmental protection. The UK government as a whole (and thus all of these public bodies) has adopted the use of a natural capital approach as a decision-making tool in its environment policy (HM Government, 2018). The natural capital approach involves an effort to value the stock of fresh water, land, air, species, minerals, and oceans which underpin the economy by producing value for people (Natural Capital Committee, 2017). This approach and its predecessors have been controversial for a range of technical and moral reasons (O'Neill, 2017), but is now being adopted and used across a range of government departments. These departments and agencies are now in the process of adapting their existing data collection and analysis efforts to bring them into line with, and allow them to support effectively, a natural capital approach. To this end, this workshop and the discussions around it were aimed at exploring the potential for COMPLEX-IT and the computational modeling within it to support and complement the implementation of a natural capital approach.

The participants emphasized the tension between natural capital as a theoretical backdrop and approach, and its application. At the core of this tension are a range of practical difficulties around data availability, analysis, and communication. We explored these issues in detail with the participants and considered how a case-based computational modeling approach might help. The following potential benefits were discussed:

- Analysis: (i) how these approaches could provide analysis tools for the overview of stocks being developed by the natural capital approach; (ii) the ability of these methods to explore trajectories of change in natural capital stocks in the search of those in high risk of collapse or significant damage; and (iii) how these methods could explore the interaction of cases (e.g. stocks), and the knock-on effects of improving one or a few, on others.

- Dealing with poor data: (i) how these approaches might offer greater flexibility on data sources used and gaps in data, than other approaches; and (ii) how feasible it is to transform existing data sets into case-based forms. 
- Communication: finally, we discussed how outputs of the analyses in COMPLEX-IT can be turned into qualitative narratives and vignettes for communication purposes.

Underpinning all of these discussions was the fundamental question of "what is a case?" for these policy practitioners using the natural capital approach. Is it an individual natural asset (such as a peat bog, a forest, or a lake), is it some aggregate of these by geography or type, or is it some geographical or administrative area? For each potential type of case, there is already data collected in one form or another, but the question of which might be best to use first, and how this might maximize the potential of any analysis, was a cornerstone of discussion throughout. It is not our aim here to explore these potentials in detail, but rather to reflect on the other side of discussions we had, the practical barriers for their realization.

\section{Barriers to the Use of Computational Modeling: Access and Ability}

Participants described, and we have observed in our own work and that of CECAN, a profound inflexibility, conventionality, and inertia in the research and evaluation commissioning process in UK government. Broadly, this appears to come from one of two sources. First, it can arise for technical and bureaucratic reasons. Various layers of oversight and quality assurance can make the hurdles which a "new" analysis or modeling approach needs to be guided through too high to allow for exploration and healthy risk-taking with methods. In addition, highly simplified models of the policy process (known to be simple, but still used to structure workstreams) can restrict the permitted points of access for research and evaluation methods to clearly contained "moments" of input. In effect, policymakers limit the access and input of research into policy processes, to clearly defined and controlled points. For complexity-appropriate computational modeling, which seeks to develop broader system understanding and inform discussions and thinking (rather than only make forecasts), through iteration and reflection, this is a serious problem. These methods are not well suited to momentary, singular, and definitive inputs into an otherwise rolling or closed process. This makes accessing them, for policy evaluators and analysts, very difficult.

The second cause of this inertia described to us by participants is driven by perceptions of what is politically necessary, rather than by technicalities. Participants described, despite a growing interest in complexity, a strong push and demand for (false) reliability in analysis and modeling. Senior civil servants, communicating with senior policymakers and politicians, want to be provided with certainty and with "numbers" that give the impression of accountability and credibility. Again, methods and modeling which take into account wholistic views of the social and policy space, and embrace uncertainty and lack of data, are not well suited to meeting these demands, meaning this demand for certainty tends to make these methods less viable and accessible for analysts. 
Setting aside these barriers for analysts being able to "officially access" complexity-appropriate modeling, there is another key barrier for their use; the ability to use them, both easily, and in combination with others. This ability is driven by two key factors, skill and data. The complexity-appropriate computational modeling approach we used, and related approaches, require specific technical competencies and skills which are not standard on undergraduate, or even many postgraduate, taught courses. This means analysts must gain these skills while in work. UK civil servants do have time for personal and skills development, but this time is inevitably constrained. On specific projects, the standard learning curves for using these methods don't work in the face of tight deadlines; it would be unacceptable, for example, to suggest an analysis project was $30 \%-50 \%$ longer in duration, so that analysts could learn and test an approach before actually applying it. We have observed many policy evaluators trying to circumvent this problem by testing out "new" methods on smaller projects, or asking for help from researchers and others informally, or pro bono. This can work to build skills but does nothing to address the systemic technical and political accessibility barriers described above. Furthermore, in UK government, staff training schemes are, in effect, highly regulated and monopolized by a few providers. This means content can be inflexible and only changes at these providers' discretion. In addition, it means that individual analysts ac- cessing courses outside the standard scheme is the exception, not the rule.

The second significant barrier to strengthening the ability to deploy complexity-appropriate modeling approaches is the perceptions and realities about the need for good data. First, the perception which we have encountered on many occasions is that models need substantial amounts of data to be validated. Thus, in complex social settings, where there is rarely lots of good data, models will not be helpful due to a lack of data. This perception is dangerous for complexity-appropriate modelers. It seems to stem from the overriding influence of economics models, in which unvalidated models are valueless, owing to their purpose of forecasting. Complexity-appropriate computational models (and COMPLEX-IT) are typically aimed at a broader set of purposes, perhaps encompassing some forecasting, in addition to improving understanding and providing an entry point for improved discussion and thinking (Gilbert et al., 2018; Johnson, 2015). Policy analysts have an acute awareness of the poor quality of their data, it is the bread-and-butter of their work, but they may also hold these economics-inspired views of what models need, and so may falsely perceive low value in them.

A more prosaic issue around data, which can lead to an inability of use, is having data in the "right" format. Though this point is simple on a conceptual level, it forms a profound barrier. If existing data cannot quickly be transformed or plugged into complexity-appropriate methods, then it is 
likely, they will not be used. This issue was particularly relevant in the discussions we had on natural capital, where there are many existing data sets, but they would require considerable transformations and processing to be used.

All of these issues around accessibility of modeling, and ability to use modeling, can come together to make modeling's use a serious challenge. Individually, most barriers can be overcome, but if two or three intersect at once, there is little chance they can all be negotiated. In our experience, only the most innovative teams within departments with the right mix of resource and flexibility can overcome them routinely; others are regularly stopped by them, even where there is interest, good will, and resource.

\section{Discussion}

$\mathrm{B}$ efore we plot a way forward for applied complexity scientists, and policy evaluators and analysts, we want to briefly outline some recent contributions from the modeling and policy research fields in the UK, which might help direct our path. First, Cairney and Oliver (2018) review the advice given in the academic and grey literature to researchers wishing to have policy impact with their research and relate this through their understanding of the policy making process (as researchers of public policy and evidence use). They find relatively consistent advice across the literature they examine, revolving around eight core suggestions to researchers: (i) do high-quality research; (ii) make research relevant and readable; (iii) understand the policy process, actors, and context; (iv) be accessible to policy makers; (v) decide if you want to be an "issue advocate" or "honest broker"; (vi) build relationships and ground-rules with policy makers; (vii) be entrepreneurial or find someone who is; and (viii) reflect continuously. They suggest these recommendations appear consistent because they are vague and safe, but they also ignore the inherent complexity of the policy process, and all the unwritten rules and structures within it. Cairney and Oliver reject the idea that researchers can easily use these "how to" guides to have impact, but rather suggest that the political and social structures of the policymaking process and its complexity, mean no impact can be guaranteed. They suggest researchers are better placed accepting these difficulties and making a more fundamental decision about how they want to spend their time; if it is on impact-related activities, they suggest prioritizing this at the expense of time for research.

Second, as modelers, Gilbert et al. (2018) provide some reflections on the use of computational modeling in public policy and outline some "key lessons" for policy modelers to realize the full potential of what modeling has to offer public policy analysis. Their key lessons are that: (i) the process of modeling is often as important as the outputs; (ii) the decision about levels of abstraction in a model is key; (iii) data and validation issues must be recognized but not used as an excuse not to model; (iv) modelers should work in an Agile and collaborative fashion; (v) 
modelers should take more interest in the ethics of policy modeling; (vi) communicating the process and outputs of modeling requires careful planning; and (vii) models need to be maintained after initial development, or after researchers have moved on.

At first glance, these lessons sound a little like the "how to" guides Cairney and Oliver (2018) critique. However, because they are focused on the practice of computational modeling, rather than solely on the activity of individual researchers, and they are focused on the success of modeling, rather on the more abstract "impact of research," we believe they are still useful. Our aim here is to combine the brutal pragmatism and realism of Cairney and Oliver (2018) and Gilbert et al.s (2018) more optimistic lessons, with our reflections on the use of complexity-appropriate computational modeling. This combination, we hope, will provide a realistic path forward for how to arrive at a point where complexity-appropriate computational modeling can be a standard analysis approach for evaluators and analysts to use when appropriate.

To break down the barriers of accessibility of methods-recall the inflexibility and inertia of the commissioning process described by our participants-we believe applied complexity scientists need to widen their efforts beyond just the methodological and analytic innovations they hope to make, but also consider the implications of these approaches for the commissioning and research design process in gov- ernment. The call for more flexible and iterative commissioning and study designs is beginning to be heard (e.g. CECAN, 2018), but we now need to know what these might look like in practice. Researchers need to put forward promising examples, and push for their use in practice. Examples might include those on how to encourage experimentation, as proposed in Brian and Carter (2016), or those which place trust in practitioners' motivation and support their learning (rather than evaluation), as in Knight, Lowe, Brossard, and Wilson (2017). Complexity scientists need to pick up on these examples, others, and their own designs, and take them to government. As Cairney and Oliver (2018) tell us, this may be at the cost of the time and effort on the methods themselves, but this is exactly the refocusing of effort by researchers which may deliver more meaningful use.

A second path here is to give complexity-appropriate methods the "official seal of approval." Following Cairney and Oliver's bluntness, we suggest doing this merely as a means to an end; the effort in doing this is unlikely to meet many standard research organizations' objectives. To do this, researchers need to understand what documents and institutions legitimize and lend credibility to methods and analysis (in the eyes of government), and then target these with their advocacy for complexity-appropriate methods. In the UK, this includes documents like the Treasury's "Magenta Book" on evaluation (HM Treasury, 2011), "Green Book" on ex-ante policy appraisal (HM Treasury, 2018), and "Aqua Book" on 
producing analysis for government (HM Treasury, 2015). This approach is already being developed in the UK; for example, CECAN is contributing to a revised version of the Magenta Book, and computational modelers are engaging with the Aqua Book (see, Edmonds, 2016).

On a more diffuse front, applied complexity scientists need to fight the demand for false, singular, definitive, and inappropriate certainty in public policy analysis. This involves a whole host of different activities, many of which they already undertake, but requires continuously challenging and reclaiming the discussion of rigor and generalization within policy analysis. Researchers should have examples on hand that highlight both success stories of complexity-appropriate methods and the failures of traditional approaches when applied to questions and issues they were not suited to. Where they do not have published examples, they should consider finding or generating their own.

To address the issues, our participants identified around skills and capacity, we suggest there is a need for a range of resources for policy evaluators and analysts, to be developed by researchers and their organizations. For example, training courses should be provided at a range of lengths, modes, and levels of study. Traditional long form courses, such as masters' modules, should be opened up to policy analysts. This will require creative thinking, such as evening classes, or semester long modules being condensed to week-long in- tensive courses. Standard shorter form courses can also be developed, targeting four hours or less, and located near the offices of policy analysts, meaning government staff actually have the time to attend. The popularity of online courses should also offer inspiration. We hope the CECAN syllabus (CECAN, 2017) is useful resource for developing such training courses.

On our participants' data issues, efforts should be made to unpack, and push back against, perceptions about the need for large amounts of rich quantitative data. Moreover, researchers may wish to be bolder in their articulation of the need for multiple cycles of theorizing, modeling, and data collection. When starting from a low base (i.e. little or no modeling done previously, and little useful theory or data) in a particular domain, it is almost always necessary for a prototype model to be developed, for theory to be gathered or developed, and for researchers to realize little usable data exists for model validation (Barbrook-Johnson, Badham, \& Gilbert, 2017). Researchers need to manage expectations around this and make clear that after one cycle of "theory-model-data," they probably won't have a model or analysis ready to be deployed directly, but rather may require several iterations with government taking part the entire time to develop something valuable. Articulating the end value here is difficult but essential; Barbrook-Johnson et al. (2017) give us one example of how to attempt it, focusing on nonpredictive uses of models in public health. There will be many other ways to do this. Address- 
ing this issue effectively will deliver on Gilbert et al's (2018) request that data issues be acknowledged but not used as an excuse to not model.

Implicit in many of these suggestions is a need for more co-produced and participatory use of complexity-appropriate methods. Cairney and Oliver (2018) remind us that this will mean ceding control of projects, but we believe this is a price worth paying if we care about making policy analysis more grounded, reflexive, and complexity-appropriate. Co-produced participatory projects will also be slower, more difficult, and perhaps even less publishable than others. Researchers need to work out ways to deal with this, and proceed nonetheless. Gilbert et al's (2018) suggestion of the process of modeling being often more valuable than the outputs is of high relevance here, researchers should keep this in mind for themselves in co-produced projects, just as much as articulate it to policy users.

\section{Conclusion}

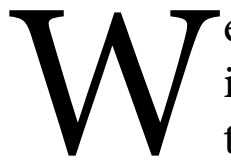

e have outlined the growing interest in complexity-appropriate modeling in policy evaluation and analysis and described some of our recent efforts to use these methods with UK government. The main barriers we find to the use of these methods, include: (i) approaches rendered inaccessible by the inflexibility and inertia of government processes; and (ii) the inability to use methods created by lack of skills and issues around data. By combining our re- flections and some recent contributions from the modeling and policy research communities, we outline paths forward for applied complexity scientists to have greater success in applying complexity-appropriate methods. In condensed form, these are:

1. Put forward new complexity-appropriate commissioning approaches and study designs for policy research and analysis.

2. Help give complexity-appropriate methods the "official seal of approval" by advocating for them in the venues and institutions that government looks to for quality assurance.

3. Constantly push back against policy makers' wish for wrong, singular, definitive, high-certainty answers.

4. Be generous, creative, and flexible in providing training and courses; make courses more accessible for policy analysts.

5. Be bold in articulating the need for methods to be developed iteratively through multiple theory-modeldata cycles.

Implied in all of these, and our discussion, is a need for researchers to work with government in a co-produced and participative manner. Beyond this, we believe researchers need to be modest and pragmatic when working with government. If we want complexity-appropriate methods to be used, relatively widely, in public policy evaluation and analysis, we need to go where the demand is for these methods, and we need to do co-production properly. 


\section{References}

Anzola, D., Barbrook-Johnson, P., \& Cano, J. I. (2017). Self-organization and social science. Computational and Mathematical Organization Theory, 23(2), 221-257. https://doi. org/10.1007/s10588-016-9224-2.

Barbrook-Johnson, P., Badham, J., \& Gilbert, N. (2017). Uses of agent-based modeling for health communication: The TELL ME case study. Health Communication, 32(8), 939-944. https://doi. org/10.1080/10410236.2016.1196414.

Barnes, M., Matka, E., \& Sullivan, H. (2003). Evidence, understanding and complexity. Evaluation 9(3), 265-284. https://doi.org/10.1177/135638900300 93003.

Brian, K., \& Carter, P. (2016). Contracts for adaptive programming. Overseas Development Institute: October 2016. Retrieved from https://www.odi.org/ sites/odi.org.uk/files/resourcedocuments/10927.pdf.

Byrne, D., \& Callaghan, G. (2014). Complexity theory and the social sciences: The state of the art. London: Routledge.

Byrne, D., \& Uprichard, E. (2012). Useful causal complexity. In H. Kincaid (Ed.), The oxford handbook of philosophy of social science (pp. 109-129). Oxford: Oxford University Press.

Cairney, P., \& Oliver, K. (2018). How should academics engage in policymaking to achieve impact? Political Studies Review. https://doi.org/
10.1177/1478929918807714.

Cairns, R., \& Krzywoszynska, A. (2016). Anatomy of a buzzword: The emergence of "the water-energy-food nexus" in UK natural resource debates. Environmental Science \& Policy, 64, 164-170. https://doi.org/10.1016/j. envsci.2016.07.007.

Callaghan, G. (2008). Evaluation and negotiated order: Developing the application of complexity theory. Evaluation, 14(4), 399-411. https://doi.org/ $10.1177 / 1356389008095485$.

Castellani, B., Rajaram, R., Gunn, J., \& Griffiths, F. (2015a). Cases, clusters, densities: Modeling the nonlinear dynamics of complex health trajectories. Complexity, 21(S1), 160-180. https:// doi.org/10.1002/cplx.21728.

Castellani, B., Rajaram, R., Buckwalter, J. G., Ball, M., \& Hafferty, F. (2015b). Place and health as complex systems: A case study and empirical test. Basel, Switzerland: Springer International Publishing.

Castellani, B., Barbrook-Johnson, P., \& Schimpf, C. (2019). Case-based methods and agent-based modelling: Bridging the divide to leverage their combined strengths. International Journal of Social Research Methodology, 22(4), 403-416. https://doi.org/10.1080/1364 5579.2018 .1563972$.

Centre for the Evaluation of Complexity Across the Nexus (CECAN) (2017). Evaluation of complex policy and programmes a CECAN module for future 
policy analysts and evaluators. November 2017. Retrieved from https://www. cecan.ac.uk/sites/default/files/2018-01/ Cecan\%20Module\%20Syllabus_17\%20 Dec.pdf.

Centre for the Evaluation of Complexity Across the Nexus (CECAN) (2018). Policy evaluation for a complex world. April 2018, Version 2.0. Retrieved from https://www.cecan.ac.uk/sites/ default/files/2018-03/CECAN\%20 Manifesto\%20Version\%202.0\%20 April\%202018\%20\%28online\%29.pdf.

Edmonds, B. (2016). Review: The aqua book: Guidance on producing quality analysis for government. Journal of Artificial Societies and Social Simulation, 19(3). Retrieved from http://jasss.soc. surrey.ac.uk/19/3/reviews/7.html.

Gates, E. (2016). Making sense of the emerging conversation in evaluation about systems thinking and complexity science. Evaluation and Program Planning, 59, 62-73. https://doi. org/10.1016/j.evalprogplan.2016.08.004

Gilbert, N., Ahrweiler, P., Barbrook-Johnson, P., Narasimhan, K. P., \& Wilkinson, H. (2018). Computational modelling of public policy: Reflections on practice. Journal of Artificial Societies and Social Simulation, 21(1), 14. https://doi.org/10.18564/jasss.3669.

Haynes, P. (2017). Social synthesis finding dynamic patterns in complex social systems. London, UK: Routledge.

HM Government (2018). A green future: Our 25 year plan to improve the environment. Retrieved from https:// www.gov.uk/government/publications /25-year-environment-plan.

HM Treasury (2011). The Magenta Book guidance for evaluation. Retrieved from https://www.gov.uk/government/ publications/the-magenta-book

HM Treasury (2015). The Aqua Book: guidance on producing quality analysis for government. Retrieved from https://www.gov.uk/government/ publications/the-aqua-book-guidanceon-producing-quality-analysis-forgovernment.

HM Treasury (2018). The Green Book central government guidance on appraisal and evaluation. Retrieved from https://www.gov.uk/government/ publications/the-green-bookappraisal-and-evaluation-in-centralgovernment.

Johnson, P. (2015). Agent-based models as "Interested Amateurs." Land, 4(2), 281-299. https://doi.org/10.3390/ land4020281.

Knight, A. D., Lowe, T., Brossard, M., \& Wilson, J. (2017). A whole new world-funding and commissioning in complexity. Collaborate Report. Retrieved from http://wordpress. collaboratei.com/wp-content/uploads/ A-Whole-New-World-FundingCommissioning-in-Complexity.pdf.

Mowles, C. (2014). Complex, but not quite complex enough: The turn to the complexity sciences in evaluation scholarship.Evaluation, 20(2), 160-175. 
https://doi.org/10.1177/13563890145 27885.

Natural Capital Committee (2017). How to do it: a natural capital workbook. Retrieved from https://www. gov.uk/government/groups/naturalcapital-committee.

O'Neill, J. (2017). Life beyond capital. Essay for the centre for understanding sustainable prosperity. Retrieved from https://www.cusp.ac.uk.

Ragin, C. C. (2009). Qualitative comparative analysis using fuzzy sets (fsQCA). In B. Rihoux \& C. C. Ragin (Eds.). Configurational comparative methods: Qualitative comparative analysis (QCA) and related techniques (pp. 87-122). Thousand Oaks, CA: Sage.

Rajaram, R., \& Castellani, B. (2012). Modeling complex systems macroscopically: Case/agent-based modeling, synergetics, and the continuity equation. Complexity, 18(2), 8-17. https:// doi.org/10.1002/cplx.21412.

Reynolds, M., Forss, K., Hummelbrunner, R., Marra, M., \& Perrin, B. (2012). Complexity, systems thinking and evaluation. Evaluation Connections: Newsletter of the European Evaluation Society. December 2012: 7-9. Retrieved from http://www.europeanevaluation. org/sites/default/files/ees_newsletter /2012-12-Connections.pdf.

Reynolds, M., Gates, E., Hummelbrunner, R., Marra, M., \& Williams, B. (2016). Towards systemic evaluation. Systems Research and Behavioral Science, 33(5),
662-673. https://doi.org/10.1002/sres. 2423.

Sanderson, I. (2000). Evaluation in complex policy systems. Evaluation, 6(4), 433-454. https://doi.org/10.1177/1356 3890022209415.

Senabre Hidalgo, E. (2018). Management of a multidisciplinary research project: A case study on adopting agile methods. Journal of Research Practice, 14(1) P1,pp. 1-17. Retrieved from http:// jrp.icaap.org/index.php/jrp/article/ view/588/489.

Stame, N. (2004). Theory-based evaluation and types of complexity. Evaluation, 10(1), 58-76. https://doi.org/10.11 77/1356389004043135.

Walton, M. (2014). Applying complexity theory: A review to inform evaluation design. Evaluation and Program Planning, 45, 119-126. https://doi.org/10.10 16/j.evalprogplan.2014.04.002.

Williams, B. (2015). Prosaic or profound? The adoption of systems ideas by impact evaluation. IDS Bulletin, 46(1), 7-16. http://dx.doi.org/10.1111/17595436.12117. 